\title{
Antimicrobial, antidermatophytic, and cytotoxic activities from Streptomyces sp. MER4 isolated from Egyptian local environment
}

\author{
Ahmed A. Hamed ${ }^{1,2^{*}}$ (D), Mohamed S. Abdel-Aziz ${ }^{1,2}$, Mohamed Fadel ${ }^{1}$ and Mohamed F. Ghali ${ }^{3}$
}

\begin{abstract}
Background: Recently, actinomycetes have attracted the attention of researchers worldwide. They can produce secondary metabolites with antibacterial, antifungal, antiviral, and antitumoral properties.

Results: Streptomyces sp. MER4 (accession no. KM099241) was isolated from the pyramid region, Giza, Egypt. This strain was previously mentioned for its ability to produce antidermatophytic bioactive metabolites. Scale-up fermentation and fractionation of the extract has been established using different solvents. The ethanol fraction exhibited a considerable antidermatophytic effect (19.8, 21.2, and $20.3 \mathrm{~mm}$ for Trichophyton mentagrophyes, Microsporum canis, and Microsporum gypseum, respectively), antimicrobial (10, 8, 7, 9, and $9 \mathrm{~mm}$ for Pseudomonas aeruginosa, Staphylococcus aureus, Candida albicans, Bacillus subtilis, and Aspergillus niger, respectively), and cytotoxic activity (inhibition of 78.48\%). Further purification of the ethanol fraction was done, and one promising compound was produced. This compound was intensely characterized and elucidated by studying its spectral date including nuclear magnetic resonance (NMR) and liquid chromatography mass spectroscopy (LC/MS). The produced compound was identified as JBIR-58 (salicylamide) derivative compound.

Conclusions: Streptomyces sp. MER4 has been identified genetically and screened for its ability to produce bioactive compound with antibacterial antitumor and antidermatophytic agent. The scale-up fermentation, purification, and structure elucidation led to pure compound named salicylamide derivatives JBIR-58 from the fermentation broth of Streptomyces sp. MER4.
\end{abstract}

Keywords: Streptomyces sp., Antimicrobial, Antidermaotophytic, Cytotoxicity, Salicylamide derivative (JBIR-58)

\section{Introduction}

Actinomycetes have been known as a group of the major soil population. They are widespread in nature and found in dry than wet soil (Wellington et al. 1992). Actinomycetes are good producers of wide diversity of structurally unique bioactive secondary metabolites with various biological activities including therapeutically and agriculturally important compounds (Tanaka and Omura 1993). Furthermore, they can produce a group of secondary

\footnotetext{
* Correspondence: ahmedshalbio@gmail.com; ahmed.shalabi@abdn.ac.uk ${ }^{1}$ Microbial Chemistry Department, National Research Centre, 33 El- Bohouth St. Dokki, Giza 12622, Egypt

${ }^{2}$ Marine Biodiscovery Centre, Department of Chemistry, University of Aberdeen, Meston Walk, Aberdeen AB24 3UE, UK

Full list of author information is available at the end of the article
}

metabolites, many of which have antibacterial or antifungal properties. Streptomyces is the major genus of Actinobacteria and in the family Streptomycetaceae (Hong et al., 2009). More than 500 species of Streptomyces have been known and identified (Lee et al. 2005). Streptomyces species are chemoorganotrophic in their mode of nutrition, filamentous Gram-positive bacteria but not acid-alcohol fast. Although they occur in the same habitat of fungi and are superficially similar, streptomycetes are not fungi (Ikeda et al. 2003). They have genomes with high-GC content 69-78\% (Kavitha et al. 2010).The filaments and spores are tiny usually $1 \mu \mathrm{m}$ or less in diameter (Willemse et al. 2011). The colonies are slow-growing and often have a soil-like smell because of production of geosmin, a 
volatile metabolite (Jüttner and Watson 2007). The most important characteristic of streptomycetes is their potency to produce secondary metabolites with antibacterial, antifungal, antiviral, and antitumoral properties. Streptomyces griseus and Streptomyces coelicolor are used for industrial production of Streptomycin and novel antibiotics such as dihydrogranticin respectively. Streptomycetes produced Doxorubicin as anticancer agents (Mukhtar et al. 2012) and the immunomodulatory agents Rapamycin. Another metabolite of Streptomycetes known as the "Geosmin" and sidrophore are responsible for the earthy odor (Sanglier et al. 1993). However, volatile product secreted by Streptomyces may also be responsible for the specific smell (Bais et al. 2012). The most antibiotics developed for human pharmaceutical use represents about $50 \%$ of all known antibiotics and are mainly come from actinomycete metabolites especially from Streptomyces spp. (Goodfellow \& Williams, 1983, Hopwood 2007). The genus Streptomyces was first illustrated by Waksman and Henrici (1943) and is considered as a rich source of bioactive natural products which are extensively used as pharmaceuticals (Fguira et al. 2005). Genus Streptomyces alone produces a large number of bioactive molecules. It has an enormous biosynthetic potential that remains unchallenged without a potential competitor among other microbial groups. A large number of Streptomyces spp. have been isolated and screened from soil in the past several decades (Watve et al. 2001).

Dermatophytes are a group of fungi that exist and live on keratin substrate and thus called "Keratinophilic fungi." These fungi were considered as the etiological agents responsible for causing skin infection (Deepika and Kannabiran 2010). Deramtophytes invade skin, hair, and nails caused as a result of fungal colonization of the keratin-containing layers of the body. Three fungal genera are mainly responsible for keratin colonization namely Trichophyton, Microsporum, and Epidermatophyton (Emmons et al. 1977; Luilma et al. 2005).

The work is undertaken with the aim of isolating different Streptomyces strains from the Egyptian habitats and screening them for their ability to produce bioactive compounds with antidermatophytic effects. Also, isolation, purification, and structure elucidation of promising compound (s) could take place. The promising Streptomyces strain could also be molecularly identified.

\section{Materials and methods Chemicals}

All reagents used were of analytical grade, and solvents were of spectroscopic grade; methanol, ethanol, dichloromethane, and ethyl acetate HPLC grade (Fischer Chemical, UK). All other media components, analytical grade chemicals, and reagents were obtained from Sigma
Chemical Co., USA, and Qualikemes Fine Chem Pvt. Ltd., India.

\section{Sampling}

Samples were collected during 2011, between June and December 2011 from soil surroundings of pyramid area. Samples were collected, kept in sterile tubes in refrigerator until processed in laboratory.

\section{Isolation of streptomycetes}

Isolation of streptomycetes from soil samples has been done using the serial dilution method of Hayakawa and Nonomura (1987). Suspensions were plated for isolation of streptomycetes. Petri dishes were prepared 1 day before plating and incubated at room temperature overnight to eliminate films of moisture on the agar surface; $0.1 \mathrm{ml}$ inocula of the proper dilution was placed on each plate and spread with a sterile glass rod using starch nitrate agar medium for isolation of streptomycetes. This medium contains $(\mathrm{g} / \mathrm{l})$ starch, 20.0; $\mathrm{KNO}_{3}, 2.0 ; \mathrm{K}_{2} \mathrm{HPO}_{4}$, 1.0; $\mathrm{MgSO}_{4} .7 \mathrm{H}_{2} \mathrm{O}, 0.5 ; \mathrm{NaCl}, 0.5 ; \mathrm{FeSO}_{4} .7 \mathrm{H}_{2} \mathrm{O}, 0.01$; $\mathrm{CaCO}_{3}$, 3.0; agar, 20.0; and distilled water $1000 \mathrm{ml}$. The $\mathrm{pH}$ was adjusted to 7.2. The inoculated plates were incubated at $28{ }^{\circ} \mathrm{C}$ and examined for streptomycete growth after 7-10 days. The isolation of streptomycetes based on their special morphological characteristics (deep sitting colonies, sporulation, characteristic color, etc.) The plates that showed countable single colonies were selected and purified by streak plate technique.

\section{Molecular identification of Streptomyces isolate P4}

Streptomyces isolate (P4) was identified according to a molecular biological protocol by DNA isolation, amplification (PCR), and sequencing of the ITS region. The primers 27F (AGAGTTTGA TCM TGG CTC Ag) and 1492R (TAC GGY TAC CTT GTTACG ACT T) were used at PCR. The purification of the PCR products was carried to remove unincorporated PCR primers and dNTPs from PCR products by using Montage PCR Clean up kit (Millipore). Sequencing was performed by using Big Dye terminator cycle sequencing kit (Applied BioSystems, USA). Sequencing products were resolved on an Applied Biosystems model 3730XL automated DNA sequencing system (Applied BioSystems, USA).

\section{Extraction of crude secondary metabolite from actinomycetes}

Spore suspensions of the candidate actinomycete strains were inoculated in $1 \mathrm{~L}$ Erlenmeyer flasks each containing $250 \mathrm{ml}$ ISP2 broth medium of the following constituents $(\mathrm{g} / \mathrm{l})$ : yeast extract, 2.0 ; malt extract, 1.0 ; and dextrose, 0.5 . The flasks were incubated on shaker at $150 \mathrm{rpm}$ rotation at $30{ }^{\circ} \mathrm{C}$ for 10 days. The cultures were centrifuged at $4{ }^{\circ} \mathrm{C}$, $5000 \mathrm{rpm}$ for $30 \mathrm{~min}$. The culture 
supernatant was extracted with $500 \mathrm{ml}$ ethyl acetate and concentrated in rotary vacuum (Augustine et al. 2005).

\section{Determination of antidermatophytic activity of crude extract from actinomycetes}

The test fungal cultures Trichophyton mentagrophytes (RCMB 09285), Microsporum canis (RCMB 07321), and Microsporum gypseum (RCMB 07336) obtained from Regional Center for Mycology and Biotechnology (RCMB), Al-Azhar University. The antidermatophytic activity of ethyl acetate extract was tested using the agar well diffusion method (Tepe et al., 2004), $100 \mu \mathrm{l}$ of the actinomycetes broth culture was placed in the wells made with a sterile cork borer on Sabouraud dextrose agar plates $(\mathrm{pH}$ 5.6) seeded with the test fungal cultures Trichophyton mentagrophytes (RCMB 09285), Microsporum canis (RCMB 07321), and Microsporum gypseum (RCMB 07336). The plates were incubated at $28{ }^{\circ} \mathrm{C}$ and observed for antibiosis after 3-4 days (Augustine et al. 2005). Amphotericin B was used as controls. The Sabouraud dextrose agar (Fluka) medium contains $(\mathrm{g} / \mathrm{l})$ peptone extract, 1.0; dextrose, 0.5; and agar, 20.0. The $\mathrm{pH}$ was adjusted to 5.6.

\section{Determination of antimicrobial activity}

The obtained extract was dissolved in 10\% dichloromethane $\left(\mathrm{CH}_{2} \mathrm{Cl}_{2}\right)$ in methanol $(\mathrm{MeOH})$ at a concentration of $1 \mathrm{mg} / \mathrm{ml}$. Aliquots of $50 \mu \mathrm{l}$ were soaked on filter paper discs (5 mm, Whatman no.1 filter paper) (Bauer et al. 1966) and dried at room temperature under sterilized conditions. The paper discs were placed on agar plates seeded with test microbes and incubated for $24 \mathrm{~h}$ at the appropriate temperature of each test organism. Both bacterial and yeast microbes were grown on nutrient agar medium. The fungal strain was on other hand grown on Czapek-Dox agar medium (DSMZ130). The culture of each microorganism was diluted by sterile distilled water to $10^{7}$ to $10^{8} \mathrm{CFU} / \mathrm{ml}$. The inoculated agar plates were first put in the refrigerator for $2 \mathrm{~h}$ and then incubated for $24 \mathrm{~h}$ (yeast and bacteria) at $37^{\circ} \mathrm{C}$ (bacteria) and $48 \mathrm{~h}$ (fungi) at $30{ }^{\circ} \mathrm{C}$. After incubation, the diameter of inhibition zones was measured against a wide range of test microorganisms comprising Gram-positive bacteria (Bacillus subtilis ATCC6633 and Staphylococcus aureus ATCC6538-P), Gram-negative bacteria (Escherichia coli ATCC14169 and Pseudomonas areuginosa ATCC27853), yeasts (Candida albicans ATCC10231 and Saccharomyces cerevisiae ATCC9080), and the fungus (Aspergillus niger NRRLA326). All test microbes were obtained from the culture collection center, Microbial Chemistry Department, National Research Center, Egypt.

\section{Evaluation of the antitumor activity against Ehrlich cell}

This test was performed using in vitro assay. Viability of tumor percentages of tumor cells which was measured by modified cytotoxic Trypan blue exclusion technique of Bennett et al. (1976). Female Swiss albino mice were kept under healthy environmental and nutritional conditions for 2 weeks then injected by Ehrlich Ascites carcinoma cells (EACC).

Ehrlich ascites carcinoma cells were isolated from previously transplanted mice after 7 days of transplantation using a sterilized syringe and obtained from Dr. Mohamed El-awady, Microbial Biotechnology Department, National Research Center. The cells were used immediately for viability study and could be diluted by phosphate buffer solution (PBS) if needed. The number of tumor cells/milliliter was calculated by using the appropriate microscope technique used culture medium which prepared using Roswel Park Mark Institute 1640 (RPMI 1640) media supplemented with $10 \%$ fetal bovine serum and $10 \%$ L-glutamine.

The viability percentages of tumor cells were measured after incubation with the examined sample as well as PBS as control. Two milliliters of Ehrlich cells $\left(1.6 \times 10^{6}\right.$ cells $/ \mathrm{ml}$ ) were added to $1 \mathrm{ml}$ sample. Then, the tubes were incubated under an atmosphere of $5 \%$ carbon dioxide at $37{ }^{\circ} \mathrm{C}$ for $72 \mathrm{~h}$. The living Ehrlich cells at the end of the 72-h incubation period were determined by a colorimetric assay based on Trypan blue solution prepared by Trypan blue (0.4\%) which was dissolved in $100-\mathrm{ml}$ distilled water and then kept in brown closed glass bottle. Ten microliters of trypan blue solution added to $10 \mu \mathrm{l}$ of sample as well as control with $80 \mu \mathrm{l}$ PBS solution and were mixed for count living cells. The number of living cells was calculated using hemocytometer slide, survival cells appeared as unstained bodies while non-viable cells were stained blue color. The in vitro results were expressed as the inhibition ratio of tumor cell proliferation calculated as:

$$
\begin{aligned}
& \text { The inhibition ratio of tumor cell proliferation }(\%) \\
& \quad=[(A-B) / A] \times 100
\end{aligned}
$$

where $A$ and $B$ are the average numbers of viable tumor cells of the control and the samples, respectively.

\section{Scale-up fermentation and extraction}

Streptomyces sp. MER4, which provide higher antidermatophyte activity, was used for scale-up fermentation on ISP2 broth medium. One-liter-volume Erlenmeyer flasks each containing $250 \mathrm{ml}$ of ISP2 medium (Pridham et al. 1956-1957) were inoculated with 5 disks of agar from well-grown subculture of this strain. The flasks were incubated at $28{ }^{\circ} \mathrm{C}$ on rotary shaker $(150 \mathrm{rpm})$ and harvested after 7 days. After centrifugation, the supernatant of each flask containing extracellular metabolites was extracted by ethyl acetate as mentioned above. In this study, ethyl acetate was selected for further 
secondary metabolite purification and isolation. Ethyl acetate extracts were concentrated in vacuo tell dryness, yielding $1.9 \mathrm{~g}$ of a reddish brown crude extract.

\section{Purification and structure elucidation of bioactive compounds}

Sephadex LH-20 column was used for the separation of different extract components. The components were separated and distributed on the stationary phase according to their molecular size. Solvent extraction and partitioning is a method to separate compounds based on their relative solubilities in two different immiscible liquids, usually water and an organic solvent. Characterization and structure elucidate for the purified compound have been established using modern spectroscopic techniques including NMR, ${ }^{13} \mathrm{C}$, and LCMS.

\section{Results}

Molecular identification of the most potent Streptomyces sp. (P4)

Sequencing of the soil isolate Streptomyces (P4), which displayed high-antidermatophytic activity in preliminary evaluation (Hamed et al. 2016), revealed high similarity (99\%) with Streptomyces spp. (Fig. 1). The (P4) presented new Streptomyces-specific sequence which was deposited in Gene Bank as Streptomyces sp. MER4 (accession number KM099241). The phylogenetic tree of the Streptomyces sp.
MER4 by applying the neighbor joining method is illustrated in Fig. 1.

\section{Fractionation of the ethyl acetate extract from liquid culture of Streptomyces sp. MER4}

Streptomyces sp. MER4 ethyl acetate extract (1.9 g) was fractionated by Sephadex LH20 column with a gradient mobile phase DCM: Methanol to yield four fractions (F1, F2, F3, and F4).F3 fractionated by liquid-liquid partition using $\left(\mathrm{H}_{2} \mathrm{O}\right.$ : n-hexane: ethanol: n-butanol) to yield another four subfractions ( $\mathrm{P} 4-\mathrm{H}_{2} \mathrm{O}, \mathrm{P} 4-\mathrm{Hex}, \mathrm{P} 4-$ but, and P4-eth). Kim et al. (2008) used Sephadex LH-20 Column for purification of protocatechualdehyde (PA) isolated from Streptomyces lincolnensis M-20. Figure 2 illustrated the overall fractionation, biological activities, and purification steps of the ethyl acetate extract from Streptomyces sp. MER4.

\section{Antidermatophytic activity of subfractions}

Ethyl acetate subfractions were assessed for their antidermatophytic activity (Figs. 2 and 3). Fraction (P4-eth) revealed the highest inhibition ratio against all dermatophytic test microbes with an inhibition zones of 19.8, 21.2, and $20.3 \mathrm{~mm}$ for Trichophyton mentagrophytes (RCMB 09285), Microsporum canis (RCMB 07321), and Microsporum gypseum (RCMB 07336), respectively. Fraction P4-water followed P4-eth with inhibition zones of 13.6, 17.4, and 15.2 for T. mentagrophytes, M. canis,

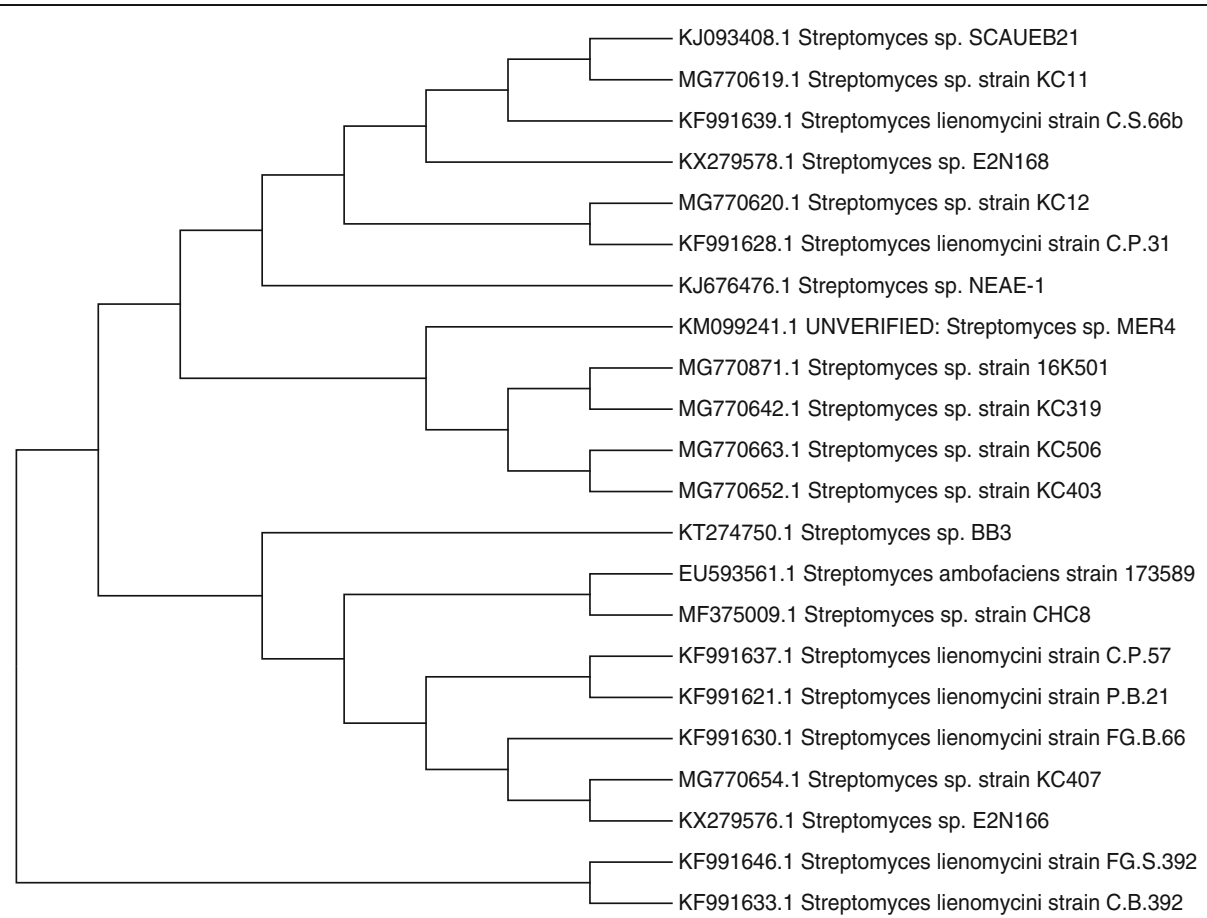

Fig. 1 Phylogenetic tree of the Streptomyces sp. MER4 strain (accession no. KM099241). The phylogenetic tree has been reconstructed using MEGA7 software 


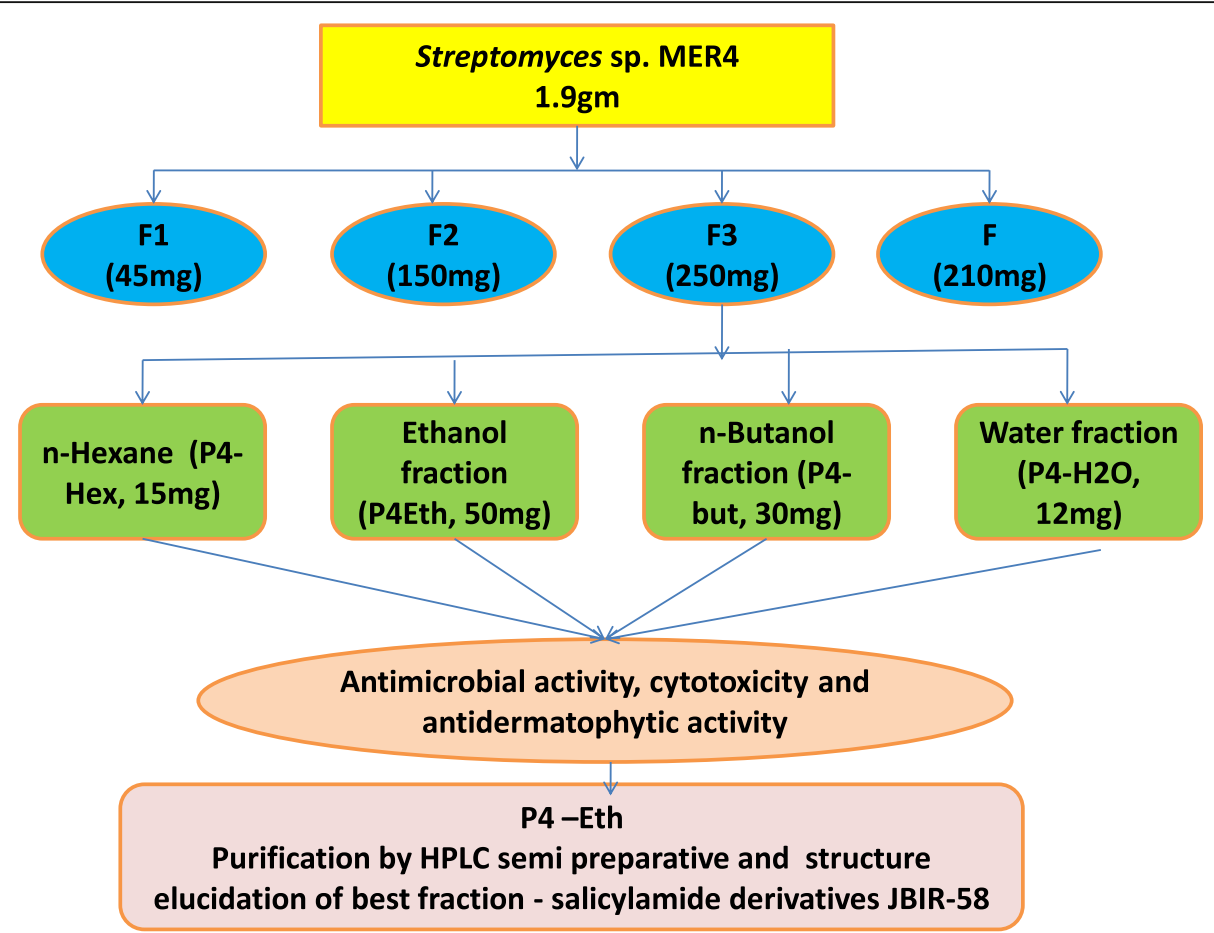

Fig. 2 Fractionation and purification scheme of Streptomyces sp. MER4 ethyl acetate extract

and M. gypseum, respectively. Moderately lower antidermatophytic effect has been reported for fraction P4-Hext with inhibition zones of 9.2, 15.2, and $12.3 \mathrm{~mm}$ for $T$. mentagrophytes, $M$. canis, and $M$. gypseum, respectively. Fraction P4-water did not show any activity against all tested dermatophytes. Amphotercin B was used as antidermatophytic standard, and it exhibited clear zones of 22.8, 20.3, and $26.7 \mathrm{~mm}$ for T. mentagrophytes, M. canis, and $M$. gypseum, respectively.
Antimicrobial activity of subfractions

The antimicrobial activities of the four subfractions were tested against (Staphylococcus aureus, Pseudomonas aeruginosa, Candida albicans, Aspergillus niger, E. coli, and Bacillus subtilis). It has been revealed that three fractions exhibited obvious antimicrobial activities (Figs. 4 and 5). The subfraction (P4-eth) showed antimicrobial activities against almost all test organisms Staphylococcus aureus (8 $\mathrm{mm})$, Pseudomonas aeruginosa $(10 \mathrm{~mm})$, Candida

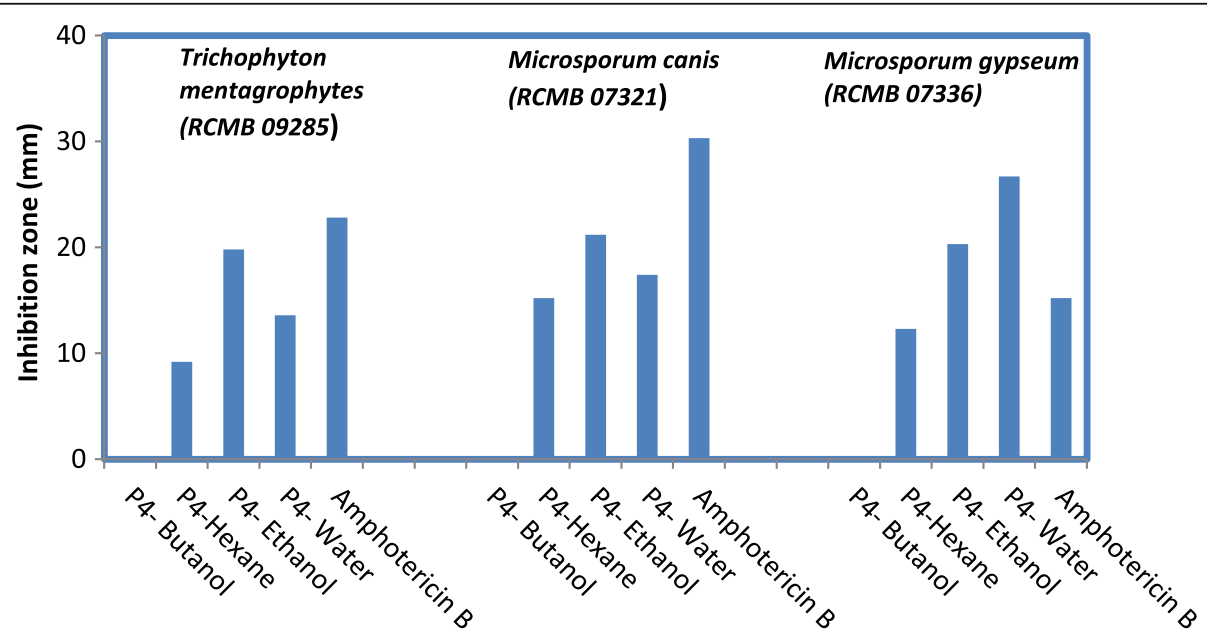

Antidermatophytic activities of P4 sub-fraction

Fig. 3 Antidermatophytic activity of subfractions from liquid-liquid partition using well diffusion method 


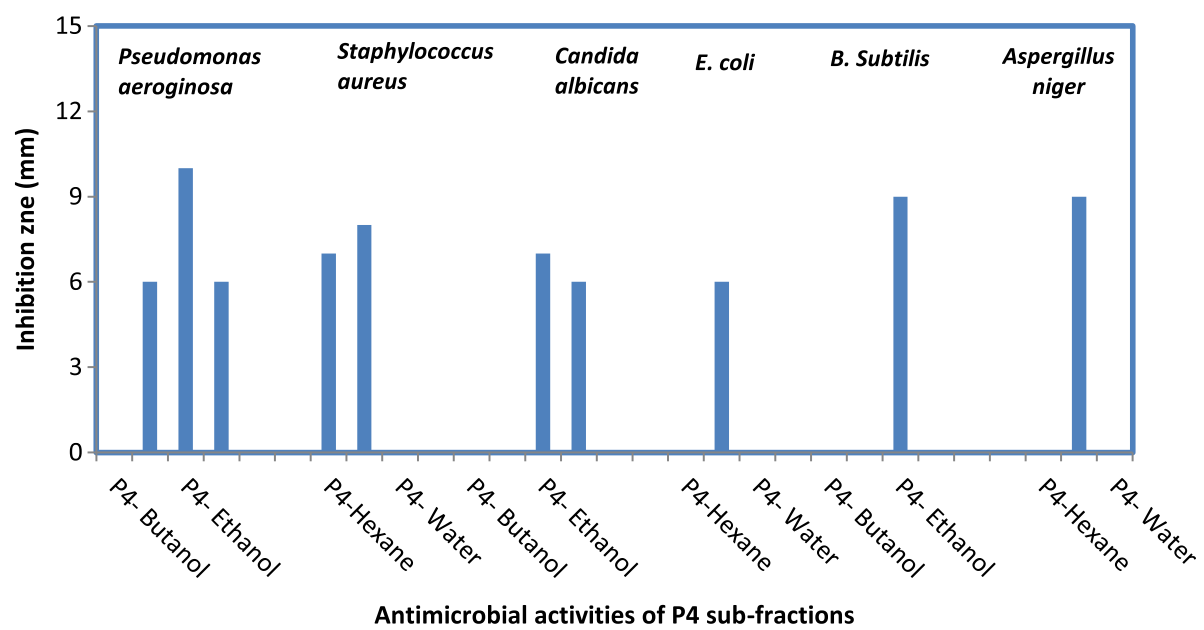

Fig. 4 Antimicrobial activity of subfractions from liquid-liquid partition using disc diffusion method

albicans (7 mm), Aspergillus niger (9), and Bacillus subtilis (9), and no activity against E.coli. Meanwhile, the subfraction (P4-hex) showed antimicrobial activities against the test organisms: Staphylococcus aureus $(7 \mathrm{~mm})$, Pseudomonas aeruginosa $(6 \mathrm{~mm})$, and E.coli $(6 \mathrm{~mm})$, and no activity against Candida albicans, Aspergillus iger, and Bacillus subtilis. Moreover, the subfraction (P4-water) showed antimicrobial activities against the test organisms Pseudomonas aeruginosa $(6 \mathrm{~mm})$ and Candida albicans (6 $\mathrm{mm}$ ), and no activity against E. coli, Staphylococcus aureus, Aspergillus niger, and Bacillus subtilis. No antimicrobial activities have been recorded for fraction P4-but. Two antimicrobial standards: neomycin (antibacterial) at concentration of $100 \mu \mathrm{g} / \mathrm{disc}$ has been used and exhibited a clear zone of $20 \mathrm{~mm}$ (Staphylococcus aureus), 23 (Bacillus subtilis), $22 \mathrm{~mm}$ (Pseudomonas aeruginosa), $17 \mathrm{~mm}$ (Candida albicans), and showed negative effect with the fungus (A. niger). Moreover, the antifungal cyclohexamide was used and exhibited a clear zone of $32 \mathrm{~mm}$ against $A$. niger.

\section{Antitumor activity of subfractions}

The antitumor activity by determined by Ehrlich Ascites carcinoma method. Hidaka et al. (1979) used Ehrlich ascites carcinoma in the examination of antitumor activity for macromomycin extracted from the culture broth of Streptomyces macromomyceticus. The biological activity of the Streptomyces sp. MER4 ethyl acetate subfractions was also evaluated, and the subfraction (P4-eth) showed the highest inhibition ratio $(78.46 \%)$ to the Ehrlich cells followed by P4-hex with an inhibition percent of 63.07 and P4-but with $32.3 \%$ cell inhibition while the P4-water fraction showed the lowest inhibition percent of $23.07 \%$ (Fig. 6).

Purification and structure elucidation of sub fraction P4-eth Pre-purified (P4-eth) fraction was further purified using high-performance liquid chromatography (HPLC) semi-preparative technique. Three milligram of the (P4-eth) fraction dissolved in $100 \mu \mathrm{l}$ of the solvent system. Then, the solvent system was pumped through the column and collected separately in Erlenmeyer flasks. The obtained fractions were dried subjected to further spectral analyses to elucidate their structures. The chemical structure of active sub-fraction (P4-Eth), isolated from Streptomyces sp. MER4 was investigated by electron ionization mass spectroscopy (EI-MS) and electron spray ionization mass spectroscopy (ESI-MS) (Additional file 1: Figure S1, Additional file 2: Figure S2 and Additional file 3: Figure S3), nuclear magnetic resonance (NMR) (Additional file 1: Figure S3), and ultraviolet (UV) spectroscopy. It was obtained as a yellow powder. The HPLC chromatogram shows that the compound separated at retention time of about $17 \mathrm{~min}$ as detected by UV (Fig. 7).

\section{Discussion}

The molecular identification of the isolated strain revealed high similarity with Streptomyces sp. and has been deposited at GenBank under the accession no. KM099241 as Streptomyces sp. MER4 (accession number KM099241). The molecular technique is now a common and accurate technique for identifying microorganisms (Chen et al. 2001), and it is now used as an alternative to the traditional inaccurate and time-consuming methods (Zhao et al. 2007). These traditional methods depend on the study of morphological, physiological, and biochemical characters as well as the parietal components, in particular the amino acids and the glucides, and these provides very distinctive specific information. However, these characters in certain cases fail to classify an isolate in only one genus (Provost et al. 1997). Therefore, molecular studies are one of the strongest and easiest methods to identification (Ramazani et al., 2010). 

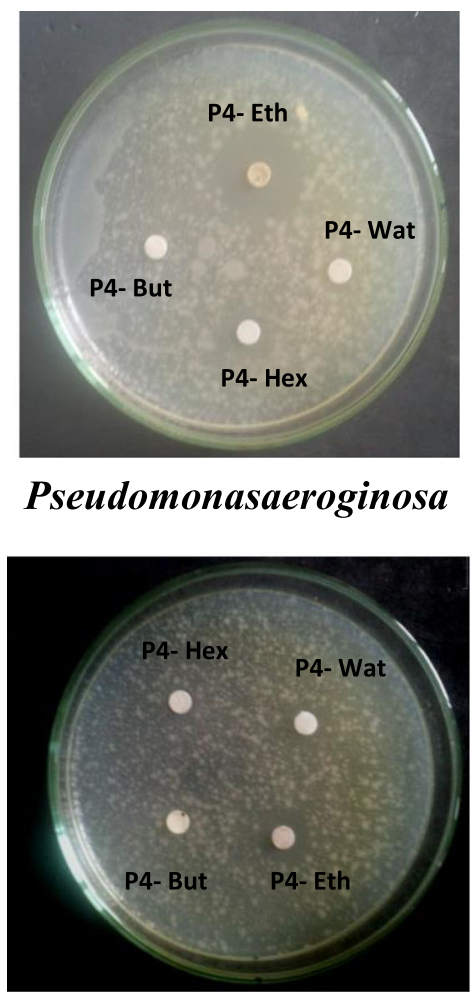

Candidaalbicans

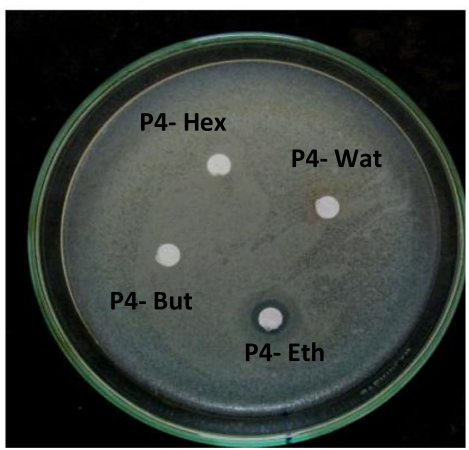

B.subtilis

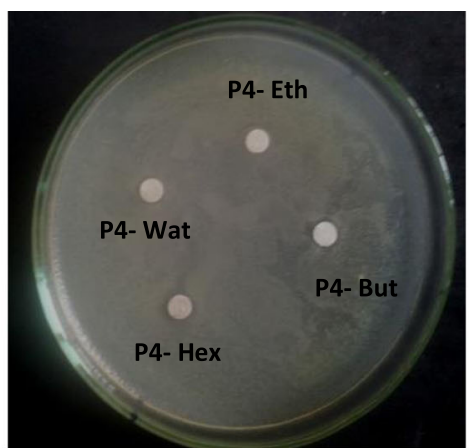

Staphylococcusaureus

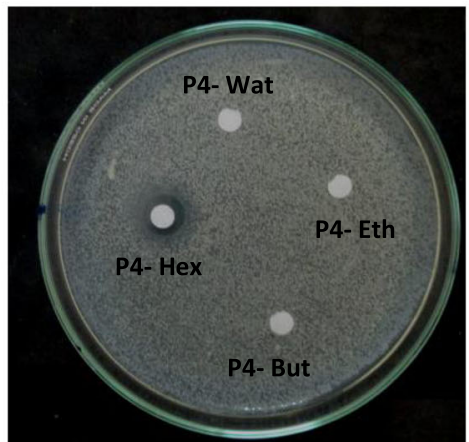

E.coli

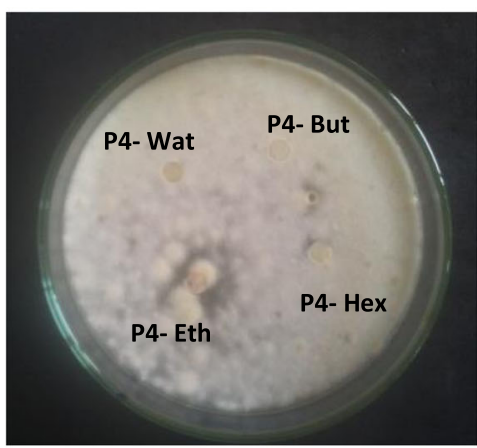

Aspergillusniger

Fig. 5 Clear zone of Streptomyces sp. MER4(P4) subfractions using disc diffusion method with different test microbes

The biological activity of the Streptomyces sp. MER4 ethyl acetate subfractions were also evaluated; one subfraction (P4-ethanol) showed the highest inhibition ratio to the Ehrlich cells. So, all the four subfractions were also assessed for antidermatophytic activity, and the highest fraction revealed the highest inhibition ratio against all dermatophytic test microbes was P4-ethanol fraction. The first report about the antidermatophytic secondary metabolites from streptomycetes was established from Streptomyces rochei AK39 (Vijyakumar et al., 2007). Three Streptomyces spp. isolated from Saltpan region exhibited potential antidermatophytic activity, and these strain were identified using $16 \mathrm{~S}$ rRNA technique as Streptomyces sp. VITDDK1, Streptomyces sp. VITDDK2, and Streptomyces sp. VITDDK3 (Deepika and Kannabiran 2009a \& b). The subfraction (P4-eth) showed broad spectra of antimicrobial activities against Staphylococcus aureus, Pseudomonas aeruginosa, Candida albicans, Aspergillus niger, and Bacillus subtilis. Another study on the crude extract from Streptomyces fradiae BW2-7 showed broad spectra of antimicrobial activities against the bacterial skin pathogen Staphyloccous aureus and Staphylococcus epidermis as well as the fungal pathogen (dermatophyte) Trichophyton rubrum 


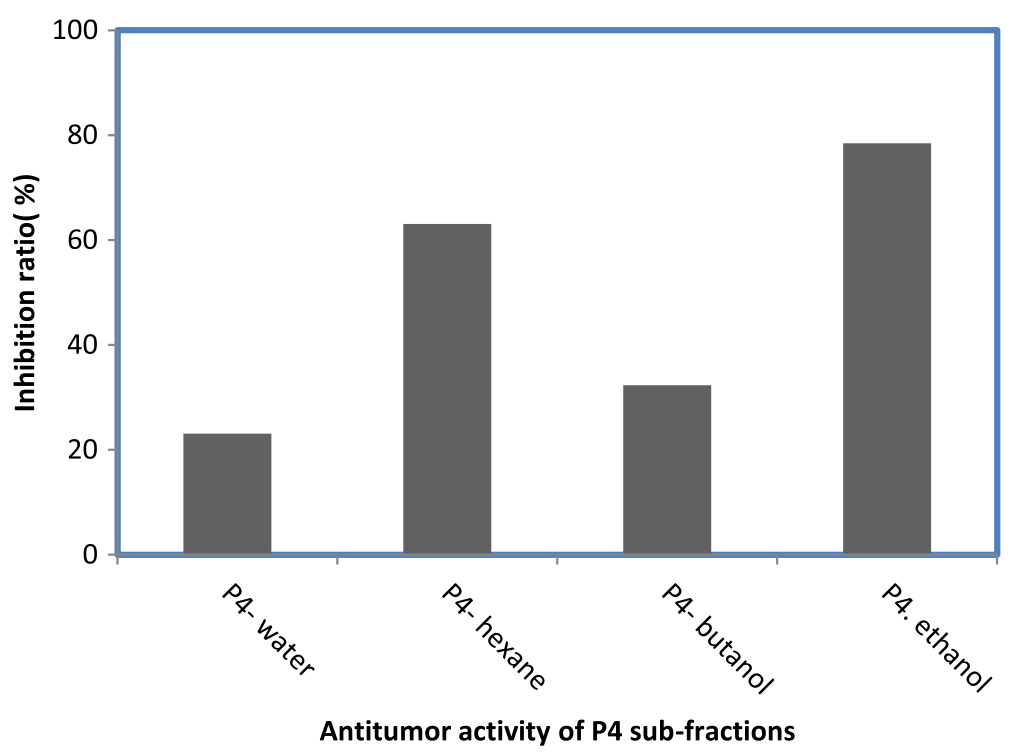

Fig. 6 Antitumor activity of Streptomyces sp. MER4 (P4) secondary metabolites fractionated from liquid-liquid partitioning

(Kumar et al. 2014). The pre-purified subfraction (P4-eth) was further purified using HPLC semi-preparative technique. The purified compound was identified using different techniques to measure the molecular weight including LC-MS, EI-MS, and ESI-MS and the spectral analysis using NMR and Proton Nuclear Magnetic Resonance (1HNMR). A search in AntiBase using the obtained data as well as the molecular weight determined by ESI-MS and EI-MS suggested that the isolated compound is very closely similar to the structure of salicylamide derivative (JBIR-58) $\left(\mathrm{C}_{14} \mathrm{H}_{15} \mathrm{NO}_{7}\right)$, which was further confirmed comparing with literatures. JBIR-58 is salicylic acid derivatives which are organic chemical compounds related to class of structurally very diverse secondary metabolites. Ueda et al. (2010) isolated salicylamide derivatives JBIR-58 from the fermentation broth of Streptomyces sp. SpD081030ME-02. Salicylic acid is a monohydroxybenzoic acid, a type of phenolic acid and a beta hydroxy acid. It is derived from the metabolism of salicin. Salicylic acid derivatives are widely used for the treatment of various diseases. For example, methyl salicylate is a natural product of many species of plants which are used in flavoring for foods, candies, beverages, and pharmaceuticals. In addition, it is used as a perfumery like magnolia, meadowsweet, and root beer. It is also used in medicine mainly for dephlogistication and analgesia (Ekinci et al. 2011).

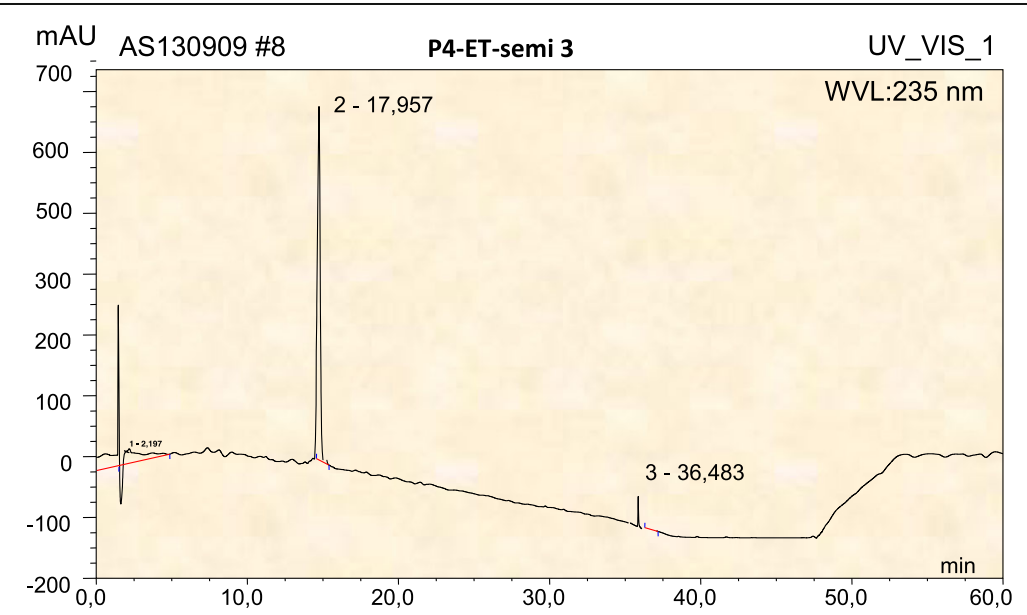

Fig. 7 HPLC chromatogram of salicylamide derivative JBIR-58 


\section{Conclusion}

Streptomyces sp. MER4 (accession number KM099241) is isolated from terrestrial environment and screened for its ability to produce bioactive compound with antibacterial antitumor and antidermatophytic agents. Moreover, the work extended to scale-up fermentation and fractionation of the produced extract and purification and structure elucidation of salicylamide derivatives JBIR-58 from the fermentation broth of Streptomyces sp. MER4.

\section{Additional files}

Additional file 1: Figure S1. El-MS spectrum of salicylamide derivative JBIR-58. (DOCX $60 \mathrm{~kb}$ )

Additional file 2: Figure S2. ESI-MS spectrum of salicylamide derivative JBIR-58. (DOCX $35 \mathrm{~kb}$ )

Additional file 3: Figure S3. ${ }^{1} \mathrm{HNMR}$ spectrum of salicylamide derivative JBIR - 58. (DOCX $1555 \mathrm{~kb})$

\section{Acknowledgements}

This work was funded by the STDF and DAAD through the cooperative project GESP no. 4299. The authors would like to thank Prof. Peter Proksch, Dr. Amal Hassan, Mrs. Claudia Eckelskemper, Mousa AlTarabeen, and Hendrik Niemann for their kind hospitality in Germany and for supporting and providing an excellent work facilities in the Institute of Pharmaceutical Biology and Biotechnology, Heinrich-Heine University, Germany.

\section{Funding}

This work was supported by the National Research Center, Science and Technology Development Fund (STDF) and German Academic Exchange Service (DAAD).

Availability of data and materials

Data are available upon request from the authors.

\section{Authors' contributions}

MA-A, MF, MG, and AH contributed to the design and implementation of the research, to the analysis of the results, and to the writing of the manuscript. AH performed the experiments. All authors read and approved the final manuscript.

\section{Ethics approval and consent to participate}

Not applicable

\section{Consent for publication}

Not applicable

\section{Competing interests}

The authors declare that they have no competing interests.

\section{Publisher's Note}

Springer Nature remains neutral with regard to jurisdictional claims in published maps and institutional affiliations.

\section{Author details}

${ }^{1}$ Microbial Chemistry Department, National Research Centre, 33 El- Bohouth St. Dokki, Giza 12622, Egypt. ${ }^{2}$ Marine Biodiscovery Centre, Department of Chemistry, University of Aberdeen, Meston Walk, Aberdeen AB24 3UE, UK. ${ }^{3}$ Botany Department, Faculty of Science, Zagazig University, Zagazig, Egypt.
Received: 1 August 2018 Accepted: 24 October 2018

Published online: 16 November 2018

\section{References}

Augustine SK, Bhvsar SP, Kapadnis BP (2005) Production of a growth dependent metabolite active against dermatophytes by Streptomyces rochei AK 39. Indian J Med Res 121:164-170

Bais Y, Nimbekar T, Wanjari B, Timande S (2012) Isolation of antibacterial compound from marine soil actinomycetes. International journal of biomedical and advance. Research 3(3):193-196

Bauer AW, Kirby WM, Sherris JC, Turck M (1966) Antibiotic susceptibility testing by a standardized single disk method. Am J ClinPathol 45(4):493-496

Bennett JM, Catovsky D, Danniel MT, Galton DAG, Graanlink HR, Sultan C (1976) Proposal for the classification of the acute leukamias. Br J Haem 33:451-458

Chen YCJD, Eisner MM, Kattar SL, Lafe RK, Bui U (2001) Polymorphic internal transcribed spacer region 1 DNA sequences identify medically important yeasts. J Clin Microbiol 39:4042-4051

Deepika TL, Kannabiran K (2009a) A morphological, biochemical and biological studies of halophilic Streptomyces sp. isolated from saltpan environment. Am J Infect Dis 5(3):207-213

Deepika TL, Kannabiran K (2009b) A report on antidermatophytic activity of actinomycetes isolated from Ennore coast of Chennai, Tamil Nadu, India. Int J Integr Biol 6(3):132-136

Deepika TL, Kannabiran K (2010) Review on dermatomycosis: pathogenesis and treatment. Nat Sci 2:726-773

Ekinci D, Senturk M, Kufrevioglu OI (2011) Salicylic acid derivatives: synthesis, features and usage as therapeutic tools. Expert Opin Therapeut Patents 21:1831-1841

Emmons CW, Bindford CH, Utz JP, KwonChung KL (1977) Dermatophytoses medical mycology, 3rd edn. Lea and Febiger, Philadelphia, pp 117-167

Fguira LF, Serge F, Raoudha BA, Lotifi M, Harmut L (2005) Purification and structure elucidation of antifungal and antibacterial activities of newly isolated Streptomyces sp. Strain US80. Res Microbiology 156:341-347

Goodfellow M, Williams ST (1983) Ecology of actinomycetes. Annu Rev Microbiol 37:189-216

Hamed AA, Abdel-Aziz MS, Fadel M, Ghali MF (2016) Antidermatophytes from bioactive secondary metabolites of local Streptomyces spp. JIPBS (2):155-165

Hayakawa M, Nonomura H (1987) Humic acid-vitamin agar, a new medium for the selective isolation of soil actinomycetes. J of Ferm Bioengin 65:501-509

Hidaka T, Yano Y, Yamashita T, Watanabe K (1979) Biological activity of macromomycin. The $\mathrm{j}$ of antibio:340-346

Hong, K., Gao, A., Xie, Q., Gao, H., zhuang, L., Yu, H., Mand Ruan, J. (2009). Actinomycetes for marine drug discovery isolation from Mangrove soils and plants in china microbiological research. Mar Drugs., 7(1), 24-44.

Hopwood DA (2007) Streptomyces in nature and medicine: the antibiotic markers. Oxford University Press, NY,USA

Ikeda H, Ishikawa J, Hanamoto A, Shinose M, Ikuchi H, Shiba T, Omura S (2003) Complete genome sequence and comparative analysis of the industrial microorganism Streptomyces avermitilis. Nat Biotechnol 21:526-531

Jüttner F, Watson S (2007) Biochemical and ecological control of geosmin and 2methylisoborneol in source waters. Appl Environ Microbiol 73(14):4395-4406

Kavitha A, Vijayalakshmi M, Sudhakar P, Narasimha G (2010) Screening of actinomycete strains for the production of antifungal metabolite. Afr J Microbiol Res 4(1):27-32

Kim KJ, Kim MA, Jung JH (2008) Antitumor and antioxidant activity of protocatechualdehyde produced from Streptomyces lincolnensis M-20. Arch Pharm Res 31:1572-1577

Kumar RM, Priyadarisini BV, Srigopalram S, Kumar S, Arasan T, Nou S (2014) Studies on a marine Streptomyces fradiae BW2-7 producing glycopeptide antibiotic vancomycin effective against skin pathogens. Scholars Academic Journal of Biosciences 2(11):746-761

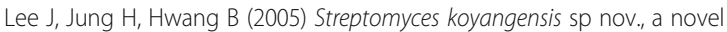
actinomycete that produces 4-phenyl-3-butenoic acid. Int J SystEvolMicrobiol 55:257-262

Luilma AG, Sidrimb JJC, Domingos TM, Cechinel VF, Vietla SR (2005) In vitro antifungal activity of dragon's blood from Croton urucurana against dermatophytes. J Ethnopharmacol 97(2):409-412

Mukhtar H, ljaz S, Ul-Haq I (2012) Production of antitumor antibiotic by Streptomyces capoamus. Pak J Bot 44(1):445-452

Pridham TG, Anderson P, Foley C, Lindenfelser HA, Hesseltine CW, Benedict RG (1956-1957) A selection of media for maintenance and taxonomic study of Streptomyces. Antib Annu pp. 947-953 
Provost F, Laurent F, Uzcategui LR, Boiron P (1997) Molecular study of persistence of Nocardia asteroides and Nocardia otitidiscaviarum strains in patients with long-term nocardiosis. J ClinMicrobiol 35(5):1157-1160

Ramazani A, Moradi S, Sorourim R, Javani S, Garshasbi M (2010) Screening for antibacterial activity of Streptomyces species isolated from Zanjan province Iran. IJPCBS 3(2):342-349

Sanglier J, Haag H, Huck T, Fehr T (1993) Novel bioactive compounds from actinomycetes. Res Microbiol 144(8):661-663

Tanaka YT, Omura S (1993) Agroactive compounds of microbial origin. Annu Rev Microbiol 47:57-87

Tepe B, Donmez E, Unlub M, Candanc F, Dafererad D, Vardar-Unlub G, Polissioud M, Sokmen A (2004) Antimicrobial and antioxidative activities of the essential oils and methanol extracts of Salvia cryptantha and Salvia multicaulis. Food Chem 84(4):519-525

Ueda J, Khan ST, Takagi M, Shinya K (2010) JBIR-58, a new salicylamide derivative, isolated from a marine sponge derived Streptomyces sp. D081030ME02. J Antibiot 63:267-269

Vijayakumar R, et al. (2007) Studies on the diversity of actinomycetes in the Palk Strait region of Bay of Bengal, India. Actinomycetologica, 21: 59-65.

Waksman SA, Hinrici AT (1943). The nomenclature and classification of the actinomycetes. J. Bacteriol. 46, 337.

Watve MG, Tickoo R, Jog MM, Bhole BD (2001) How many antibiotics are produced by the genus Streptomyces? Arch Microbiol 176(5):386-390

Wellington EMH, Stackbrandet E, Sarder D, Wolstrup J, Torgensen NOG (1992)

Taxonomic status of Kitasatosporia and proposed unification with Streptomyces on the basis of phenotypic and 16SrRNA analysis and emendation of Streptomyces

Willemse J, Borst J, Waal E, Bisseling T, Wezel G (2011) Positive control of cell division: FtsZ is recruited by SsgB during sporulation of Streptomyces. Genes Dev 25:89-99

Zhao GZ, Liu XZ, Wu WP (2007) Helicosporus hyphomycetes from China. Fungal Diversity. 26:313-524

\section{Submit your manuscript to a SpringerOpen ${ }^{\circ}$ journal and benefit from:}

- Convenient online submission

- Rigorous peer review

- Open access: articles freely available online

- High visibility within the field

- Retaining the copyright to your article

Submit your next manuscript at $\boldsymbol{\nabla}$ springeropen.com 